Check for updates

Cite this: J. Mater. Chem. C, 2017, 5, 10794

Received 14th July 2017,

Accepted 22nd September 2017

DOI: $10.1039 / \mathrm{c} 7 \mathrm{tc0} 03155 f$

rsc.li/materials-c

\section{Improved structural order by side-chain engineering of organic small molecules for photovoltaic applications $\dagger$}

\author{
T. Han, $\ddagger^{a}$ I. Bulut, $\ddagger^{b}$ S. Méry, ${ }^{c}$ B. Heinrich, ${ }^{c}$ P. Lévêque, ${ }^{a}$ N. Leclerc iD $\star^{b}$ and \\ T. Heiser ${ }^{a}$
}

\begin{abstract}
Despite obvious progress in organic semiconducting material design and organic bulk-heterojunction solar cell power conversion efficiencies the rationalization of the molecular design to finely tune organic semiconductor properties is still challenging. Herein, thanks to a particular dumbbell-shaped molecular design allowing partial decoupling between the structural properties and the frontier energy level positioning and optical absorption properties, we demonstrate the impact of the nature of side chains along the conjugated backbone on the structural properties of conjugated molecules. Thus, linear side chains on the structurally cohesive triazatruxene building blocks of our molecules provide higher stacking abilities, resulting in higher charge transport abilities and photovoltaic performances. These dumbbell-shaped molecules are a promising molecular family for reaching high solar cell efficiencies as well as for understanding in detail the impact of chemical structure on optoelectronic properties.
\end{abstract}

\section{Introduction}

Solution-processed organic bulk heterojunction (BHJ) solar cells have attracted significant attention in the last few decades due to their potential for low cost, lightweight and flexible solar modules, environmentally friendly elaboration processes, as well as for low energy feedback times and good recyclability. ${ }^{1,2}$ Since the seminal work of M. Leclerc et al. and Y. Liu et al. on highly efficient donor/acceptor alternated conjugated materials, ${ }^{3,4}$ the power conversion efficiencies of organic solar cells has been increasing continuously, exceeding nowadays $13 \% .^{5}$ This increase in performance is the outcome of improved device architecture and design of new organic semiconducting materials. ${ }^{6}$ However, despite this noticeable progress, the rationalization of the molecular design of high performance organic semiconductors is still challenging. This is due in particular to the strong interdependence of (macro-)molecular parameters that can impact the optoelectronic and structural

\footnotetext{
${ }^{a}$ ICube UMR 7357, Université de Strasbourg-CNRS, 23 rue du Loess, 67037 Strasbourg, France. E-mail: thomas.heiser@unistra.fr

${ }^{b}$ ICPEES UMR 7515, Université de Strasbourg-CNRS, 25 rue Becquerel, 67087 Strasbourg, France. E-mail: leclercn@unistra.fr

${ }^{c}$ IPCMS UMR 7504, Université de Strasbourg-CNRS, 23 rue du Loess, 67034 Strasbourg, France

$\dagger$ Electronic supplementary information (ESI) available: Experimental techniques, synthesis details, cyclic voltammetry curve and SAXS patterns at high temperature. See DOI: $10.1039 / \mathrm{c} 7 \mathrm{tc} 03155 \mathrm{f}$

\$ These authors contributed equally to this work.
}

properties of organic semiconductors, as well as the efficiency of optoelectronic organic devices. ${ }^{7}$ For instance, Y. Geerts et al. recently demonstrated that the charge carrier mobility in a series of benzothieno[3,2-b][1]benzothiophene (BTBT) molecules can be changed by orders of magnitude by varying only the side-chain position. ${ }^{8}$ Similarly, R. K. Castellano et al. showed that the chirality of commonly used 2-ethylhexyl solubilizing chains can have a significant effect on the morphology and optimum processing conditions of small molecule organic thin films used as photovoltaic device active layers. ${ }^{9}$

Further progress in the development of high performing materials strongly requires the design of specific organic semiconducting molecules for which the structural properties (and hence the charge transport properties) could be decoupled from the frontier energy level positioning and the optical absorption properties. In this respect, we recently initiated the design of "dumbbell-shaped" molecules, composed of a central dye placed between two discotic peripheral units based on 10,15-dihydro-5H-diindolo-[3,2- $a: 3^{\prime}, 2^{\prime}$-c] carbazole units, also called triazatruxene (TAT). TAT is a $C_{3}$ symmetric planar $\pi$-extended conjugated structure, which can be considered as a structural moiety made of three fused carbazole units, with a strong electron-donating character. In these TAT-dye-TAT designs, the TAT units are supposed to promote intermolecular $\pi-\pi$-stacking interactions and thereby facilitate charge transport, while the molecular structure of the selected dye should allow one to tune rather independently the photon harvesting and electrochemical properties of the molecules. ${ }^{10}$ In addition, as 
alkyl chains can be grafted onto the amine groups of the TAT unit, high solubility in common solvents can be reached independent of the nature of the central dye unit. Several series of dumbbell-shaped molecules carrying TAT terminal units have been previously reported by us and used as solution-processable electron donor molecules in BHJ solar cells. ${ }^{11}$ The results achieved so far support the idea that the high planarity of TAT moieties promotes $\pi$-orbital overlap and improves charge transport and collection efficiency in BHJ devices. However, for some TAT-dye-TAT derivatives, in which the TAT units were functionalized with ramified alkyl chains while non-substituted units were used as the central dye, the materials were amorphous and led to poor charge transport and charge extraction abilities. ${ }^{10}$ These observations suggest that the side chain position and nature may strongly impact the optoelectronic properties of the TAT-based dumbbell-shaped molecules, similar to what has been reported previously for other $\pi$-conjugated materials. ${ }^{12}$

In this work, our aim is to investigate deeper the relationship between the side-chains and properties of TAT-based dumbbellshaped molecules. For this purpose, we designed, a new series of TAT-dye-TAT molecules containing thienopyrroledione (TPD) as the electron withdrawing group of the central chromophore. The use of the TPD dye was motivated by its excellent electrondeficient character and by its possibility for easy alkylation, independent of the TAT units. Thus, different side-chain combinations were explored, using two octyl chain isomers of different bulks, namely a linear octyl chain (C8) and a ramified 2-ethylhexyl chain (EH). The compounds are then labelled $\mathrm{TPD}_{\mathrm{x}}-\mathrm{TAT}_{\mathrm{x}}$, where $\mathrm{x}=\mathrm{C}_{8}$ or/and $\mathrm{EH}$, leading to a series of four molecules (see Scheme 1). The impact of the alkyl chains on the molecular and thin film properties was studied, with particular emphasis on microstructure and charge transport aspects. The side-chain nature was found to dramatically affect the intermolecular interactions in the solid state as well as the charge transport and photovoltaic properties, as evidenced by various investigations i.e. UV-vis absorption spectroscopy in solution and thin films, differential scanning calorimetry (DSC), polarized optical microscopy (POM), small angle X-ray scattering (SAXS) experiments, as well as hole mobility measurements and photovoltaic device characterization. More particularly, the hole mobility and the power conversion efficiency of $\mathrm{BHJ}$ devices based on TAT $_{\mathrm{x}}-\mathrm{TPD}_{\mathrm{x}}:[6,6]$-phenyl-C ${ }_{71}$-butyric acid methyl ester $\left(\mathrm{PC}_{71} \mathrm{BM}\right)$ blends depends critically on the choice of side-chain grafted on the TAT unit. Our results clearly show that the strongest impact is produced by the side-chains located on the TAT units, confirming that the latter are the major driving force for molecular self-assembly.

The synthetic route used for the four molecules is shown in Scheme 1 and detailed in the ESI. $\dagger$ The pinacol derivative of the TAT unit was prepared following the procedure described in a previous report, ${ }^{11 b}$ while the thienopyrrolodione (TPD) derivatives were prepared according to a procedure found in the literature. ${ }^{13}$ The central chromophores 1 and 2, were prepared by carrying out a Stille cross-coupling between the 2-trimethyltinthiophene and dibromo-TPD derivatives. A subsequent electrophilic dibromination using $N$-bromosuccinimide (NBS) afforded the compounds 3 and 4, carrying $\mathrm{C}_{8}$ and $\mathrm{EH}$ alkyl chains on the TDP unit, respectively. Finally, Suzuki cross-coupling reactions between pinacol-TAT derivatives and dibrominated compounds 3 and $\mathbf{4}$ afforded the final dumbbell-shaped molecules in reasonable coupling yields of about 45 to $60 \%$ after purification. All compounds were characterized by standard NMR and mass analyses.

In order to screen the potential of the molecules for application as electron-donor species in organic $\mathrm{BHJ}$ photovoltaic devices, we evaluated the frontier energy levels of molecules by cyclic voltammetry (CV). CV measurements have been performed in dichloromethane solution (see ESI $\dagger$ ). In line with the UV-visible absorption spectra in solution (Fig. 1a), all four molecules naturally show identical $\mathrm{CV}$ frontier levels with HOMO and LUMO values at -5.3 and $-3.3 \mathrm{eV}$, respectively, leading to a CV energy-gap of $2.0 \mathrm{eV}$ (Table 1). For $\mathrm{PC}_{71} \mathrm{BM}$, the HOMO and LUMO values measured under similar conditions are $-5.8 \mathrm{eV}$ and $-4.2 \mathrm{eV}$, respectively. ${ }^{11 a}$ The resulting LUMO offset for the electron-acceptor and the electron-donor is sufficiently high $(0.9 \mathrm{eV})$, to efficiently promote exciton dissociation. ${ }^{14}$ Moreover, as the expected open-circuit voltage $\left(V_{\mathrm{oc}}\right)$ in $\mathrm{BHJ}$ solarcells is proportional to the difference between the HOMO of the electron-donor and the LUMO of $\mathrm{PC}_{71} \mathrm{BM}$ minus an empirically determined $0.3 \mathrm{~V},{ }^{15}$ we could expect for all molecules a favourable $V_{\text {oc }}$ value, equal to $(5.3-4.2)-0.3=0.8 \mathrm{~V}$.

The UV-visible absorption spectra (in solution and in thin films) of the $\mathrm{TAT}_{\mathrm{x}}-\mathrm{TPD}_{\mathrm{x}}$ molecules are shown in Fig. 1. The absorption spectra measured in chloroform solutions overlap almost perfectly (Fig. 1a and Table 1), revealing that the charge delocalization is not affected by the side chains. We may

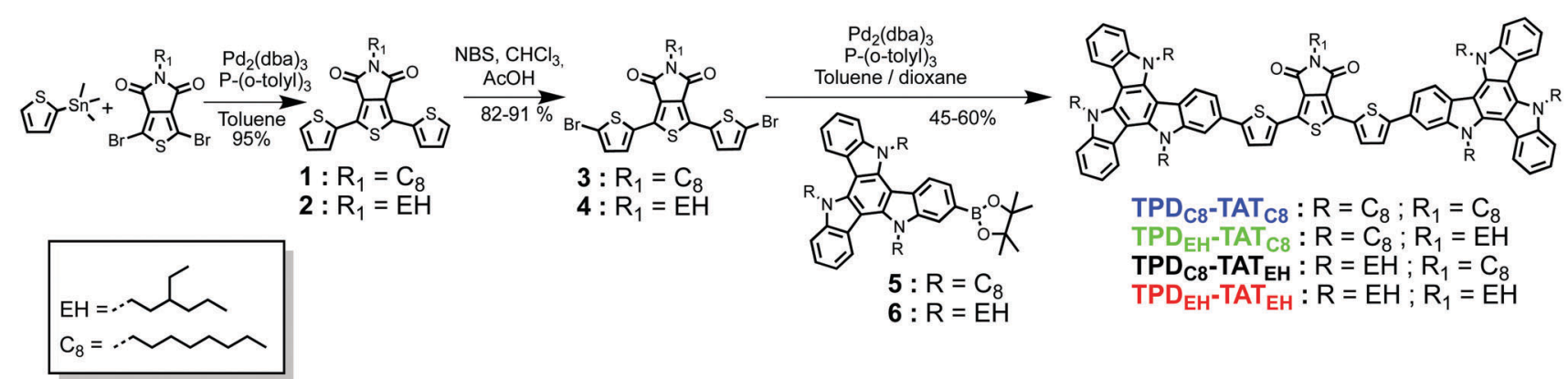

Scheme 1 Synthetic route towards the preparation of the TPDX-TAT molecules. 

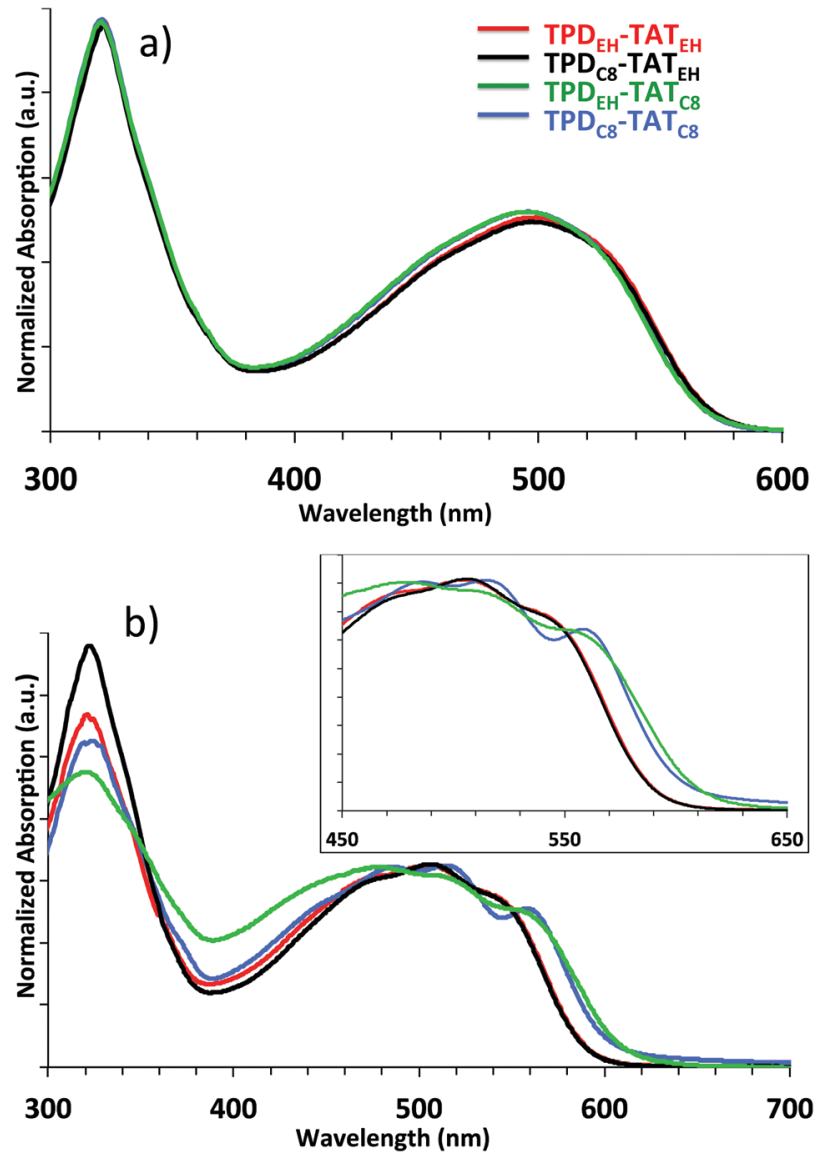

Fig. 1 Normalized absorption in chloroform solution (a) and in thin-film (b) of TPD-TAT molecules (in onset, zoom in on the ICT bands). The normalization has been performed on the $\sim 500 \mathrm{~nm}$ absorption peak.

therefore conclude that both linear and branched chains do not affect the molecular conformation and the related conjugation length in solution as confirmed by DFT calculations (see ESI $\dagger$ ). The strong absorption peak at about $320 \mathrm{~nm}\left(\varepsilon=145000 \mathrm{M}^{-1} \mathrm{~cm}^{-1}\right)$ may be assigned to $\pi-\pi^{*}$ transitions of the fused tris-carbazole (i.e. TAT) platform, ${ }^{16}$ while the broad absorption band around $500 \mathrm{~nm}\left(\varepsilon=73000 \mathrm{M}^{-1} \mathrm{~cm}^{-1}\right)$ is likely due to an internal charge transfer between the electron-rich TAT unit and the electronpoor TPD unit.

In the solid-state, all the spectra are red-shifted and broadened, with a clear impact of the side-chain nature on the optical properties (Fig. 1b). Indeed, the absorption spectra of $\mathrm{TPD}_{\mathrm{C} 8}-\mathrm{TAT}_{\mathrm{EH}}$ and $\mathrm{TPD}_{\mathrm{EH}}-\mathrm{TAT}_{\mathrm{EH}}$ (i.e. molecules with ramified side-chains on the TAT moieties) were found to show a weak bathochromic shift $(20 \mathrm{~nm})$ with almost no vibronic structure, while the spectra of the molecules with linear chains on the TAT units (i.e. $\mathrm{TPD}_{\mathrm{C} 8}-\mathrm{TAT}_{\mathrm{C} 8}$ and $\mathrm{TPD}_{\mathrm{EH}}-\mathrm{TAT}_{\mathrm{C} 8}$ ) exhibit larger red-shifts (35 nm and $40 \mathrm{~nm}$, respectively) and include marked vibronic peaks.

The thin film optical band gaps are estimated at $2 \mathrm{eV}$ and $2.1 \mathrm{eV}$ for $\mathrm{TAT}_{\mathrm{C} 8^{-}}$and $\mathrm{TAT}_{\mathrm{EH}}$-based molecules respectively. These results suggest that the less-sterically demanding linear chains on the TAT units lead to a higher structural order (better defined vibronic features) and more pronounced intermolecular interactions (larger red-shift) in the solid state. On the other hand, the chain substitution on TPD does not notably change the optical properties. These findings give therefore evidence that the intermolecular interactions of these dumbbell-shaped molecules are essentially controlled by the bulkiness of the side chain functionalization on the TAT units, and as a corollary, the TAT unit assemblies are the major driving force for molecular self-assembly. The different selfassembly behaviours of the $\mathrm{TAT}_{\mathrm{EH}}$ and $\mathrm{TAT}_{\mathrm{C} 8}$ platforms loom large in the polymorphism of the four samples, as evidenced by POM and DSC investigations (see Fig. 2). Indeed, the molecules bearing $\mathrm{TAT}_{\mathrm{EH}}$ units only show the isotropic glass and liquid states with a glass transition temperature at $T_{\mathrm{G}}=75-80{ }^{\circ} \mathrm{C}$, while those bearing $\mathrm{TAT}_{\mathrm{C} 8}$ exhibit a rich polymorphism depending on the thermal history (Table 1). More specifically, the initial frozen birefringent state flows to a fluid nematic phase beyond $T_{\mathrm{G}}$, which is located at the same temperature for all molecules. The transition to the isotropic liquid state is then reached at $156-158{ }^{\circ} \mathrm{C}$, and the fluid and glassy states of the nematic phase are successively re-obtained on cooling. The liquid-crystalline phase is however metastable and a slow crystallization process occurs on second heating above $T_{\mathrm{G}}$. This crystalline phase melts at $165-170{ }^{\circ} \mathrm{C}$, thus above the clearing temperature in the nematic state, which is therefore a monotropic phase in the sense that it can only be obtained on cooling from the isotropic liquid, but not on heating from the crystal. In any case, phase sequences are the same with nearly identical transition temperatures for $\mathrm{TPD}_{\mathrm{C} 8}-\mathrm{TAT}_{\mathrm{C} 8}$ and $\mathrm{TPD}_{\mathrm{EH}}-\mathrm{TAT}_{\mathrm{C} 8}$, confirming that the molecular organization is driven by the peripheral chains on TAT units, whatever the nature of the chain on TPD.

Table 1 Small molecules physical-chemical properties. Phase transitions and enthalpy changes for the dumbbell-shaped molecule series

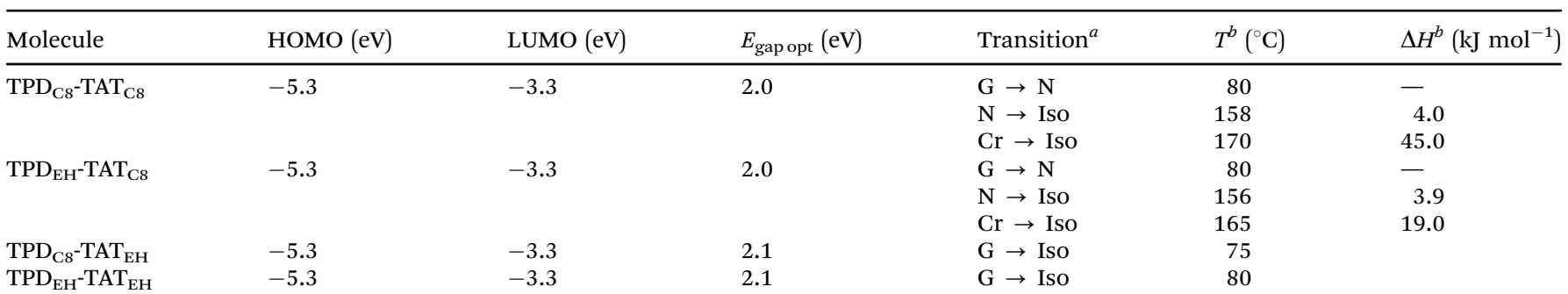

${ }^{a}$ Nature of the phases (G: glassy state or glassy nematic state; N: fluid nematic state; Cr: crystalline phase; Iso: isotropic liquid phase). ${ }^{b}$ Transition temperatures and associated enthalpy changes from DSC second and third heating runs. 

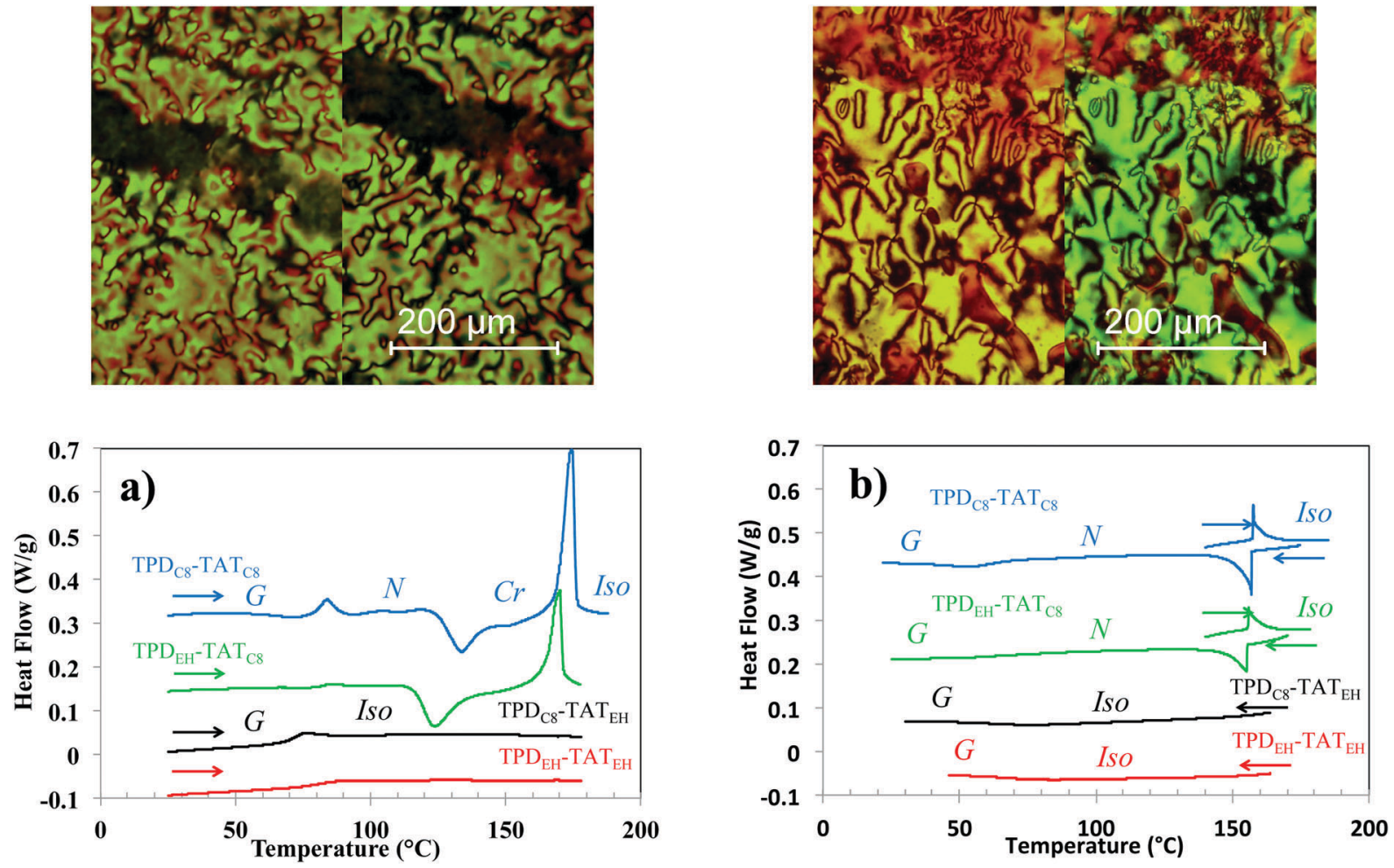

Fig. 2 (top) POM: typical nematic schlieren textures observed for the liquid-crystalline phase of $\mathrm{TPD}_{\mathrm{C} 8}-\mathrm{TAT}_{\mathrm{C} 8}$ (left) and $\mathrm{TPD}_{\mathrm{EH}}-\mathrm{TAT}_{\mathrm{C} 8}$ (right), at $150{ }^{\circ} \mathrm{C}$ in the fluid state, and at $20^{\circ} \mathrm{C}$ in the glassy state (half-images left and right, respectively); bottom, DSC: (a) 2nd heating run from glassy nematic or isotropic room temperature states (G); (b) cooling run from the fluid isotropic liquid state (Iso) and 3 rd heating run from the fluid nematic phase $(\mathrm{N})$ at $125{ }^{\circ} \mathrm{C}$; $\mathrm{Cr}$ : crystalline phase; ramp conditions: $5^{\circ} \mathrm{C} \mathrm{min}^{-1}$, endotherm up.

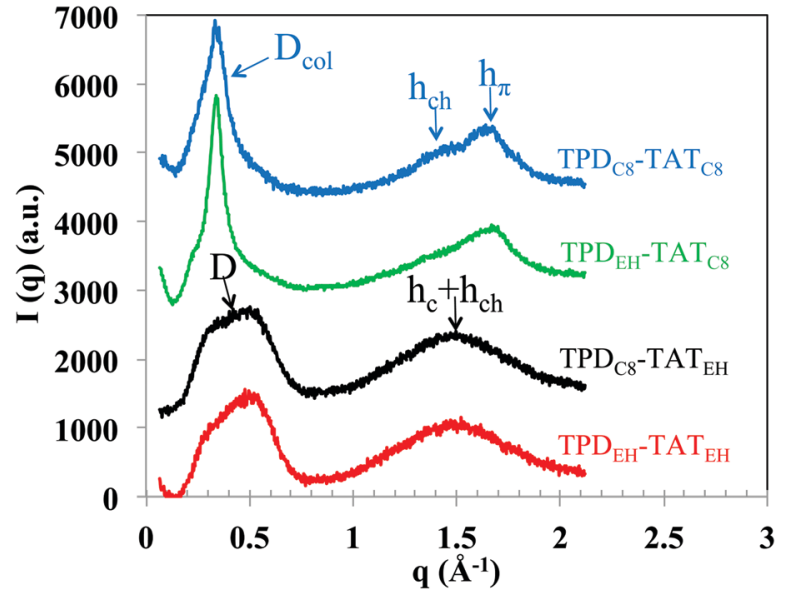

Fig. 3 SAXS patterns measured on pure materials at room-temperature.

Small Angle X-Ray Scattering experiments (SAXS) at glassy room-temperature evidence the differences of self-organization, depending on the bulk of the alkyl side-chains grafted on the TAT moieties (Fig. 3).

When TAT bear C8 chains, the SAXS patterns in the frozen mesophase are typical of a nematic columnar organization, with two characteristic broad wide-angle scattering maxima from lateral distances between molten chains $\left(h_{\mathrm{ch}} \sim 4.5 \AA\right)$ and between face-to-face piled conjugated segments $\left(h_{\pi} \sim 3.8 \AA\right)$, besides a strong peak at small-angles $\left(D_{\text {col }} \sim 18 \AA\right)$ due to average distances between TAT columns spaced by aliphatic and TPD moieties.

In both molecules where TAT bear $\mathrm{EH}$ side chains, the patterns are characteristic of amorphous compounds with (i) the disappearance of the $\pi$-stacking maximum and (ii) the persistence of a unique broad signal for lateral distances between the conjugated and aliphatic segments $h_{\mathrm{c}}+h_{\mathrm{ch}}$. The alternation of zones containing each type of antagonistic segment persists at the local range, as proven by the presence of diffuse small-angle scattering $(D \sim 10$ to $20 \AA)$. Finally, the differences of polymorphism and molecular packing in the series comes down essentially to the supramolecular organization of TAT columns induced by $\mathrm{C} 8$ chains versus the absence of supramolecular association with EH chains. This fact is likely to originate from the different cross-sections of both chain types, which is double for $\mathrm{EH}\left(42-43 \AA^{2}\right.$ at $\left.20{ }^{\circ} \mathrm{C}\right)$, so that the overall cross-section of the three ramified chains would exceed the envelope area of the TAT columns, preventing de facto the formation of the columns. ${ }^{11 b}$ With C8 chains, the piling up is in contrast authorized and thus the arrangement of the so-formed columns into the nematic phase can take place. Moreover, the close-packing along columns presumably initiates the crystallization process on second heating, explaining why it only occurs with TAT $_{\mathrm{C} 8}$. Regarding the chain carried by TPD, its presence in the periphery of the columns does not impact the 
Table 2 Hole mobility values determined from OFETs and SCLC measurements. Main average photovoltaic parameters and their uncertainties estimated on 12 devices and maximum PCE values

\begin{tabular}{|c|c|c|c|c|c|c|c|}
\hline Molecule & $\mu_{\mathrm{h}}^{a}\left(\mathrm{~cm}^{2} \mathrm{~V}^{-1} \mathrm{~s}^{-1}\right)$ & $\mu_{\mathrm{h}}^{b}\left(\mathrm{~cm}^{2} \mathrm{~V}^{-1} \mathrm{~s}^{-1}\right)$ & $V_{\mathrm{oc}}(\mathrm{V})$ & $J_{\mathrm{sc}}\left(\mathrm{mA} \mathrm{cm} \mathrm{cm}^{-2}\right)$ & $\mathrm{FF}(\%)$ & PCE (\%) & $\mathrm{PCE}_{\max }(\%)$ \\
\hline $\mathrm{TPD}_{\mathrm{C} 8}-\mathrm{TAT}_{\mathrm{C} 8}$ & $(2.8 \pm 0.8) \times 10^{-4}$ & $(2.3 \pm 0.8) \times 10^{-3}$ & $(0.78 \pm 0.01)$ & $(8.2 \pm 0.4)$ & $(57 \pm 4)$ & $(3.7 \pm 0.4)$ & 4.1 \\
\hline $\mathrm{TPD}_{\mathrm{EH}}-\mathrm{TAT}_{\mathrm{C} 8}$ & $(4.9 \pm 1.8) \times 10^{-5}$ & $(1.8 \pm 0.7) \times 10^{-3}$ & $(0.78 \pm 0.01)$ & $(6.5 \pm 0.2)$ & $(48 \pm 3)$ & $(2.4 \pm 0.2)$ & 2.6 \\
\hline $\mathrm{TPD}_{\mathrm{C} 8}-\mathrm{TAT}_{\mathrm{EH}}$ & $(2.6 \pm 0.1) \times 10^{-5}$ & $(4.7 \pm 2.9) \times 10^{-5}$ & $(0.83 \pm 0.01)$ & $(4.3 \pm 0.1)$ & $(40 \pm 1)$ & $(1.4 \pm 0.1)$ & 1.5 \\
\hline $\mathrm{TPD}_{\mathrm{EH}}-\mathrm{TAT}_{\mathrm{EH}}$ & $(4.5 \pm 0.4) \times 10^{-5}$ & $(3.8 \pm 0.9) \times 10^{-5}$ & $(0.81 \pm 0.01)$ & $(2.0 \pm 0.1)$ & $(36 \pm 1)$ & $(0.60 \pm 0.05)$ & 0.6 \\
\hline
\end{tabular}

piling of TAT units, but could just influence the arrangement of the columns through its contribution to the overall volume. However the partial volume of $\mathrm{EH}$ and $\mathrm{C} 8$ chains differ by less than $1 \%$ and hence, the nature of the chain of TPD (EH vs. C8) has no importance, in accordance with experimental findings.

In short, the design of the alkyl chains grafted on the TAT units is crucial for the molecular organization while the chain on TPD is limited to a minor role.

To investigate the influence of the chains on the electronic properties of the $\mathrm{TPD}_{\mathrm{x}}-\mathrm{TAT}_{\mathrm{x}}$ thin films, charge-carrier mobility measurements have been performed on as-deposited $\operatorname{TPD}_{\mathrm{x}}-\mathrm{TAT}_{\mathrm{x}}$ thin films (amorphous phase) using organic field-effect transistors (OFETs) and space-charge-limited current (SCLC) devices. The fieldeffect mobility data extracted from the OFET transfer characteristics in the saturation regime are summarized in Table 2. Relatively low hole mobility values (around 3-4 $\times 10^{-5} \mathrm{~cm}^{2} \mathrm{~V}^{-1} \mathrm{~s}^{-1}$ ) are observed for all molecules except for $\mathrm{TPD}_{\mathrm{C} 8}-\mathrm{TAT}_{\mathrm{C} 8}$ for which an almost ten times higher value is obtained. This observation seems at a first sight to be in conflict with the SAXS and UV-visible absorption data, for which both molecules with $\mathrm{TAT}_{\mathrm{C} 8}$ units exhibited similarly reinforced self-association (see above). However, we have to keep in mind that charge transport in OFETs occurs only within the first few molecular layers near the interface between the dielectric and may be impacted by the film morphology in this region, which is not probed in this study. At this stage, it is worth mentioning that the moderate in-plane hole mobility values do not predestine the high $\mathrm{BHJ}$ solar cell efficiencies, since the photovoltaic energy conversion is dependent mostly on charge transport across the film (i.e. the bulk mobility). Additional information on this issue can be gained from the SCLC mobility measurements (Fig. 4 and Table 2). The results show a clear dependence on the TAT substituents: the SCLC hole mobility increases by a factor of 50 (from $4 \times 10^{-5} \mathrm{~cm}^{2} \mathrm{~V}^{-1} \mathrm{~s}^{-1}$ to $2 \times 10^{-3} \mathrm{~cm}^{2} \mathrm{~V}^{-1} \mathrm{~s}^{-1}$ ) range, when using $\mathrm{C} 8$ instead of EH chains. On the other hand, the side-chains on the central TPD unit have only a minor influence on the bulk mobility (30\% difference in mobility for $\mathrm{TPD}_{\mathrm{x}}-\mathrm{TAT}_{\mathrm{C} 8}$ and $75 \%$ for $\mathrm{TPD}_{\mathrm{x}}-\mathrm{TAT}_{\mathrm{EH}}$, where $\mathrm{x}=\mathrm{C}_{8}$ or $\mathrm{EH}$ ).

These observations are thus in-line with the SAXS and spectroscopy results and confirm that the stacking of TAT moieties drives the intermolecular interactions. Also, the minor influence of the TPD substituent on the mobility corroborates the idea that charge transport in such dumbbell-shaped molecules can be controlled at least to some extent by the planar end-groups, independently of the central dye unit.

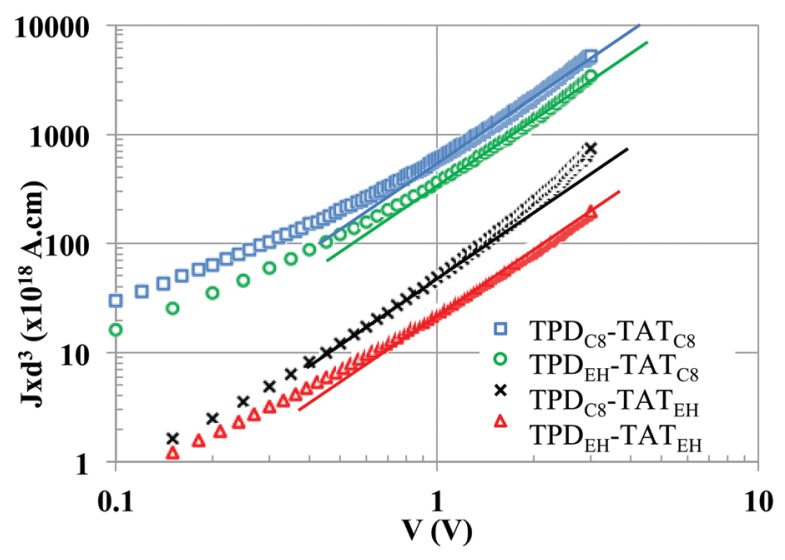

Fig. $4(J-V)$ measurements on SCLC devices (symbols). The continuous lines represent the expected variations of $J$ as a function of $V^{2}$. The current-density has been scaled by the device thickness $(d)$ to the power of three in order to highlight the difference in charge carrier mobility.

Then, we investigated the influence of the alkyl chains on the photovoltaic properties by using our molecules as electrondonor (D) material in $\mathrm{TPD}_{\mathrm{x}}-\mathrm{TAT}_{\mathrm{x}}: \mathrm{PC}_{71} \mathrm{BM}$ blends, using inverted device architecture. Details on the device structure and their elaboration and characterization procedures are given in the ESI. $\dagger$ The main photovoltaic parameters are summarized in Table 2. Optimum performances have been obtained after a post-deposition thermal treatment at $80{ }^{\circ} \mathrm{C}$ for $10 \mathrm{~min}$. Typical current-voltage curves obtained after optimization of the blend deposition process are shown in Fig. 5.

The optimum $\mathrm{TPD}_{\mathrm{x}}-\mathrm{TAT}_{\mathrm{x}}: \mathrm{PC}_{71} \mathrm{BM}$ weight ratio $(1: 1.5)$ and processing conditions were similar for all molecules. It then appears that the nature of the peripheral chains does not impact significantly the $\mathrm{PC}_{71} \mathrm{BM}$ load for which the exciton dissociation efficiency and charge collection are optimized. The $V_{\text {oc }}$ values are close to those expected from the molecular HOMO and LUMO levels $(\approx 0.8 \mathrm{~V}) .{ }^{15}$ The other photovoltaic parameters are all found to vary substantially from one molecule to the other. The short circuit currentdensity $\left(J_{\mathrm{sc}}\right)$ increases continuously from the less-ordered $\mathrm{TPD}_{\mathrm{EH}}-\mathrm{TAT}_{\mathrm{EH}}$ molecule to the more ordered $\mathrm{TPD}_{\mathrm{C} 8}-\mathrm{TAT}_{\mathrm{C} 8}$ one as well as the FF increases from $36 \%$ for $\mathrm{TPD}_{\mathrm{EH}}-\mathrm{TAT}_{\mathrm{EH}}$ to $57 \%$ for $\mathrm{TPD}_{\mathrm{C} 8}-\mathrm{TAT}_{\mathrm{C} 8}$.

Consequently, the maximum measured PCE drops from $4.1 \%$ for the more structurally organized molecule bearing only short $\mathrm{C}_{8}$ alkyl side-chains $\left(\mathrm{TPD}_{\mathrm{C} 8}-\mathrm{TAT}_{\mathrm{C} 8}\right.$ ) to $0.6 \%$ for the molecule exclusively bearing bulky $\mathrm{EH}$ chains $\left(\mathrm{TPD}_{\mathrm{EH}}-\mathrm{TAT}_{\mathrm{EH}}\right)$. 


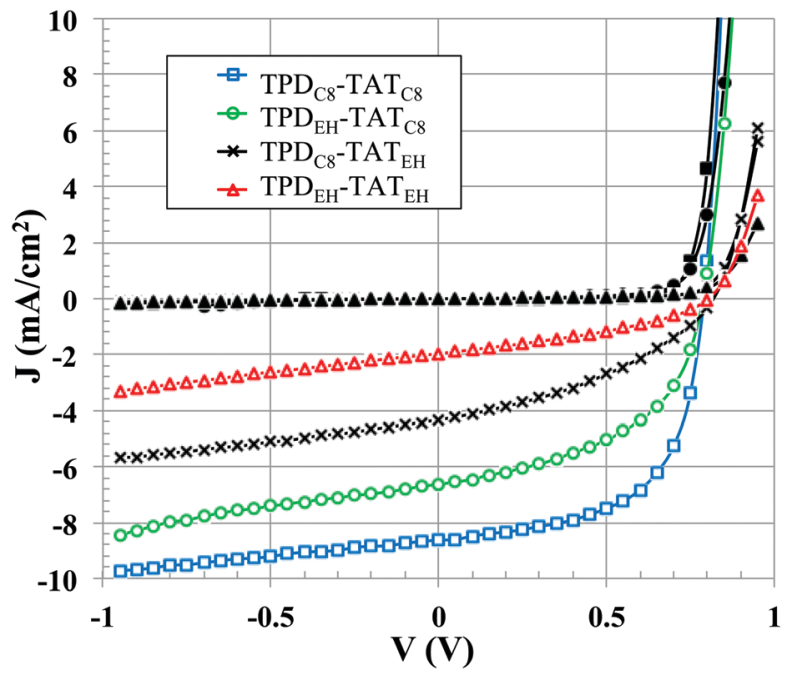

Fig. 5 ( $J-V$ measurements in the dark (closed symbols) and under standard AM 1.5G (100 mW cm${ }^{-2}$ ) illumination conditions (open symbols).

Finally, considering the relatively high optical band gap of the molecules $(\approx 2.0 \mathrm{eV})$, the PCE value of $4.1 \%$ obtained with the more ordered molecules $\left(\mathrm{TPD}_{\mathrm{C} 8}-\mathrm{TAT}_{\mathrm{C} 8}\right)$, appears as quite a fair performance when compared to the benchmark P3HT (PCE typically obtained $\sim 3-4 \%$ ) of a similar band gap. ${ }^{17}$

\section{Conclusions}

In conclusion, by performing an extensive investigation of a series of four dumbbell-shaped molecules of the same $\pi$-conjugated structure but carrying peripheral chains of two different isomers of different bulks (octyl linear vs. 2-ethylhexyl branched), we made significant achievements.

We demonstrated that all the chains substituted to the conjugated backbone do not all have the same impact on the structural properties of the molecules. As a matter of fact, the molecular self-assembly appeared to be driven by the stacking of TAT units and consequently, the bulkiness of the chains connected to them: the linear chains led to nematic and crystal phases, while the bulkier branched ones led to amorphous states. The nature of the chain on TPD has in contrast no significant influence.

We also demonstrated the high sensitivity of organic photovoltaic devices on chemical parameters that could appear at first sight as secondary. Indeed, if alkyl side chains do not affect directly the molecular optoelectronic properties, their impact on the self-assembling properties appears to be one of the predominant factors influencing device performances.

As a consequence, the more structurally ordered molecule leads to the highest PCE, equalling the one obtained with the P3HT reference polymer with a similar energy band-gap. In addition, this work demonstrates that the lateral $\pi$-stacking platforms of dumbbell-shaped molecules provide high stacking abilities, resulting in good charge transport properties in the direction perpendicular to the substrate-plane, along with efficient charge-extraction and reasonably high fill factors.
Finally, the fine molecular design of the dumbbell-shaped molecules constitutes a promising route towards efficient solutionprocessable donor molecules for high performance BHJ photovoltaic devices.

\section{Conflicts of interest}

There are no conflicts to declare.

\section{Acknowledgements}

This work has been supported by the French National Research Agency (ANR ORION project, ANR-13-PRGE-0001) and the Interreg IV-A program under project C25 Rhin-Solar.

\section{Notes and references}

1 Y. Zhou, C. Fuentes-Hernandez, T. M. Khan, J.-C. Liu, J. Hsu, J. W. Shim, A. Dindar, J. P. Youngblood, R. J. Moon and B. Kippelen, Sci. Rep., 2013, 3, 1536.

2 (a) S. Zhang, L. Ye, H. Zhang and J. Hou, Mater. Today, 2016, 19, 533-543; (b) C. McDowell and G. C. Bazan, Curr. Opin. Green Sustainable Chem., 2017, 5, 49-54.

3 S. H. Park, A. Roy, S. Beaupré, S. Cho, N. Coates, J. S. Moon, D. Moses, M. Leclerc, K. Lee and A. J. Heeger, Nat. Photonics, 2009, 3, 297-303.

4 Y. Liang, D. Feng, Y. Wu, S.-T. Tsai, G. Li, C. Ray and L. Yu, J. Am. Chem. Soc., 2009, 131, 7792-7799.

5 W. Zhao, S. Li, H. Yao, S. Zhang, Y. Zhang, B. Yang and J. Hou, J. Am. Chem. Soc., 2017, 139, 7148-7151.

6 W. Cao and J. Xue, Energy Environ. Sci., 2014, 7, 2123-2144.

7 Z. B. Henson, K. Mullen and G. C. Bazan, Nat. Chem., 2012, 4, 699-704.

8 Y. Tsutsui, G. Schweicher, B. Chattopadhyay, T. Sakurai, J.-B. Arlin, C. Ruzié, A. Aliev, A. Ciesielski, S. Colella, A. R. Kennedy, V. Lemaur, Y. Olivier, R. Hadji, F. Castet, S. Osella, D. Dudenko, D. Beljonne, J. Cornil, P. Samorì, S. Seki and Y. H. Geerts, Adv. Mater., 2016, 28, 7106-7114.

9 R. Bou Zerdan, N. T. Shewmon, Y. Zhu, J. P. Mudrick, K. J. Chesney, J. Xue and R. K. Castellano, Adv. Funct. Mater., 2014, 24, 5993-6004.

10 I. Bulut, P. Lévêque, B. Heinrich, T. Heiser, R. Bechara, N. Zimmermann, S. Méry, R. Ziessel and N. Leclerc, J. Mater. Chem. A, 2015, 3, 6620-6628.

11 (a) T. Bura, N. Leclerc, R. Bechara, P. Lévêque, T. Heiser and R. Ziessel, Adv. Energy Mater., 2013, 3, 1118-1124; (b) I. Bulut, P. Chávez, A. Mirloup, Q. Huaulmé, B. Heinrich, A. Hébraud, S. Méry, R. Ziessel, T. Heiser, P. Lévêque and N. Leclerc, J. Mater. Chem. C, 2016, 4, 4296-4303; (c) I. Bulut, Q. Huaulmé, A. Mirloup, P. Chávez, S. Fall, A. Hébraud, S. Méry, B. Heinrich, T. Heiser, P. Lévêque and N. Leclerc, ChemSusChem, 2017, 10, 1878-1882. 
12 J. Min, C. Cui, T. Heumueller, S. Fladischer, X. Cheng, E. Spiecker, Y. Li and C. J. Brabec, Adv. Funct. Mater., 2016, 26, 5032-5038.

13 P. Berrouard, S. Dufresne, A. Pron, J. Veilleux and M. Leclerc, J. Org. Chem., 2012, 77, 8167-8173.

14 J. L. Brédas, D. Beljonne, V. Coropceanu and J. Cornil, Chem. Rev., 2004, 104, 4971-5004.
15 M. C. Scharber, D. Mühlbacher, M. Koppe, P. Denk, C. Waldauf, A. J. Heeger and C. J. Brabec, Adv. Mater., 2006, 18, 789-794.

16 C. Ruiz, J. T. López Navarrete, M. C. Ruiz Delgado and B. Gómez-Lor, Org. Lett., 2015, 17, 2258-2261.

17 M. T. Dang, L. Hirsch and G. Wantz, Adv. Mater., 2011, 23, 3597-3602. 